\title{
DESAFIOS AMBIENTAIS PÓS PANDEMIA
}

\author{
Michele de Souza Fanfa ${ }^{1}$ \\ Caroline Martello ${ }^{2}$ \\ Maria do Rocio Fontoura Teixeira ${ }^{3}$
}

Resumo: Apesar da importância do oceano e da urgência de sua conservação, ainda há muito descaso com esse ambiente. A partir da reflexão sobre essas implicações, esta pesquisa traz quatro projetos ambientais do litoral do Rio Grande do Sul para trabalhar essas e outras questões baseadas nas provocações trazidas pelo filósofo Bruno Latour. Com abordagem qualitativa, a pesquisa teve por objetivo ouvir os representantes de cada projeto, tendo sido a coleta de dados realizada por meio de entrevista semiestruturada, com a aplicação de um questionário. As respostas dos educadores trazem temas emergentes e urgentes nos dias de hoje, fazendo conexões com um passado manchado por desastres ambientais e um presente e futuros possíveis, após o cenário da pandemia.

Palavras-chave: Bruno Latour; Sustentabilidade; Praia; Projeto Ambiental.

Abstract: Despite the importance of the ocean and the urgency of their conservation, there is still a lot of disregard for this environment. Thinking about these implications, this research brings four environmental projects from the coast of Rio Grande do Sul to work these and other questions based on the provocations brought by the philosopher Bruno Latour. With a qualitative approach, the research aimed to listen to the representatives of each project and the data collection was carried out through a semi-structured questionnaire. The answers of environmentalists bring up emerging and urgent themes these days, making connections with a past tainted by environmental disasters and a possible present and futures after the pandemic.

Keywords: Bruno Latour; Sustainability; Beach; Environmental Project.

1 Universidade Federal do Rio Grande do Sul. E-mail: fanfami@gmail.com,

Link para o Lattes: http://lattes.cnpq.br/9612791594479984

2 Universidade Federal do Rio Grande do Sul. E-mail: carolinemartello@gmail.com.

Link para o Lattes: http://lattes.cnpq.br/4621610724398120

${ }^{3}$ Universidade Federal do Rio Grande do Sul. E-mail: mrfontoura@gmail.com.

Link para o Lattes: http://lattes.cnpq.br/6975295280564336

Revbea, São Paulo, V. 15, № 4: 488-506, 2020. 


\section{Introdução}

"Este é um fato sólido: somos uma população confinada na superfície de uma esfera, com recursos limitados, flutuando no espaço gelado, aquecida pelo sol."

Geraldo Freire Dias (2014).

A divisão entre natureza e sociedade no mundo moderno têm pautado nossa compreensão coletiva e nossas ações em uma ideia dualista de mundo. Com a distinção de duas zonas ontológicas: de um lado a dos humanos (sociedade/sujeito) e, de outro, a dos não humanos (natureza/objeto) (LATOUR 2016). Essa divisão levou a outras cisões como o "[...] abismo ontológico que separa o mundo-em-si (natureza) das representações simbólicas (pertencentes ao 'mundo' social da linguagem)" (LIMA et al., 2019) e que tem nos deixado adormecidos frente a problemas ambientais, tais como a poluição atmosférica e do oceano, o aquecimento global e a escassez de água potável.

Com isso, criaram-se sistemas e situações sociais que dificultaram as relações entre os humanos e dos humanos com seu meio (natureza). Em virtude de um comportamento voltado para o consumo exacerbado, que contraria a lógica da sobrevivência de qualquer espécie na terra. Utilizando sem controle os bens naturais e, consequentemente, sem a preocupação necessária sobre os efeitos de suas decisões, hábitos e atitudes.

$\mathrm{O}$ cuidado com a natureza e o respeito às tradições foram esquecidos à medida que os interesses econômicos, de consumo e de poder tomaram a direção das ações humanas. Recorrendo a Bauman, é possível dizer que:

Os verdadeiros poderes que moldam as condições sob as quais todos nós agimos hoje em dia fluem num espaço global, enquanto nossas instituições de ação política permanecem, em seu conjunto, presas ao chão; elas são, tal como antes, locais (BAUMAN, 2004, p. 122).

Pautada nesta postura antropocêntrica da sociedade, as questões relacionadas ao meio ambiente foram ganhando importância econômica, social e cultural. Dessa forma, Guimarães (1995, p. 12) afirma que "[...] o ser humano, totalmente desintegrado do todo, não percebe mais as relações de equilíbrio da natureza. Age de forma totalmente desarmônica sobre o ambiente, causando grandes desequilíbrios ambientais".

Entretanto, a sociedade é totalmente dependente dos recursos naturais, desde o ar que respiramos até o alimento que colocamos em nossas mesas. Sem a natureza como um todo, sem seus ciclos, de oxigênio, carbono, nitrogênio, entre outros como o ciclo hidrológico, os seres humanos não conseguem sobreviver no globo terrestre. A terra se desenvolve através de 
uma reciclagem constante, mas nem tudo é reciclado e ela acaba por devolver aquilo que não é viável e possível reciclar e renovar.

Para Latour (2016), a crise do meio ambiente, na contemporaneidade, é consequência da tentativa da modernidade de separar a natureza das ações humanas, e propõe que se perceba que essa época jamais conseguiu efetivar essa separação, ou em suas palavras, essa purificação. No entanto, esse projeto moderno de separação total entre humanos e não humanos, sociedade e natureza, não teria efetivamente sido perpetrado:

O buraco de ozônio é por demais social e por demais narrado para ser realmente natural; as estratégias das firmas e dos chefes de Estado, demasiado cheias de reações químicas para serem reduzidas ao poder e ao interesse; o discurso da ecosfera, por demais real e social para ser reduzido a efeitos de sentido. Será nossa culpa se as redes são ao mesmo tempo reais como a natureza, narradas como o discurso, coletivas como a sociedade? Será que devemos segui-las abandonando os recursos da crítica, ou abandoná-las posicionando-nos junto ao senso comum da tripartição crítica? (LATOUR, 2016, p. 12).

E, portanto, para Latour a realidade é natural, mas não é só natural, é social, mas não é só social, é discursiva, mas não é só discursiva (LIMA et al., 2019), ela é tudo isso se relacionando em uma rede com agentes humanos e não-humanos.

Assim, este artigo, propõe uma discussão de como podemos lidar com questões ambientais pós a pandemia por meio de análises feitas com grupos atuantes em questões ambientais no litoral do Rio Grande do Sul (RS), a partir de questionamentos e inquietações trazidas por Bruno Latour, em seu texto traduzido por Déborah Danowski, "Imaginando gestos que barrem o retorno ao consumismo e à produção insustentável pré-pandemia".

$O$ artigo se inicia pela discussão de questões ambientais, seguido da apresentação da metodologia, dos resultados e sua discussão e, por fim, as considerações finais.

\section{A crise ambiental: algumas questões}

Os problemas relacionados às questões ambientais já são discutidos a bastante tempo e entre vários países. Depois da $1^{\text {a }}$ Conferência sobre Meio Ambiente, ocorrida em Estocolmo (1972), outros eventos como, reuniões e encontros, aconteceram para debater a temática: como por exemplo, a $1^{\underline{a}}$ Conferência Mundial sobre o Clima (1979), a Conferência de Toronto sobre Mudanças do Clima (1988), e os relatórios do Painel Internacional sobre Mudanças Climáticas (IPCC), criado pela Organização Meteorológica Mundial (OMM) e pelo Programa das Nações Unidas para o Meio Ambiente (ONU Meio 
Ambiente), para sintetizar e divulgar informações científicas sobre as mudanças climáticas e formular estratégias de resposta (DIAS, 2014).

Em janeiro de 2012, a ONU divulgou que o Brasil é o terceiro país do mundo a perder vidas em desastres naturais. As pessoas por ingenuidade, desinformação ou pela própria exclusão social, acabam se submetendo a situações de alto risco, como casas improvisadas em encostas e construções de prédios irregulares (DIAS, 2014). Para piorar esse cenário desastroso temos que conviver com a irresponsabilidade de gestões públicas corruptas, que não dão a devida importância para as questões ambientais, como o ocorrido em Muzema no Rio de Janeiro em 2019, construídos por milicianos com materiais não apropriados e em áreas de risco $(G 1,2019)$.

Segundos Dias (2014) ao lado da ambição dos desmatamentos e a ganância da especulação imobiliária, vinha os deslizamentos de terras e soterramento de bairros inteiros. Entre esses desastres, são descritos por Dias:

[...] a crise dos incêndios florestais ladeava os danos das secas; o massacre da fauna juntava-se ao aumento das pragas, perdas de safras e crescimento das epidemias; a irresponsabilidade da poluição em todas as suas formas acompanhava o crescimento das doenças degenerativas; 0 excesso de exploração dos recursos naturais para atender ao consumismo exacerbado já resultava em desequilíbrio ecológico percebido por todos; [...]o lucro vinha embalado em vulnerabilidade social traduzida em desemprego, miséria e violência. A erosão ética dava a amálgama para corrupção, alimentada pela crescente ignorância (p. 20).

A espécie humana é a única que ocupa espaços retirando o que ali existe, destruindo as matas ciliares, assoreando nascentes, fazendo tudo que é possível para moldar a Terra ao seu favor e a qualquer custo. Juntando todas as manobras de destruição dos recursos naturais, o homem se aproxima, cada vez mais, e com finalidades diferentes dos animais silvestres, tanto para usar como alimento ou para domesticar as espécies.

A fauna silvestre é o recurso natural menos compreendido no Brasil. Ela se tornou vítima de nossa ignorância sobre a estrutura e a dinâmica dos ecossistemas nacionais. Não é possível conservar a fauna, num sentido amplo, oferecendo-se aos animais apenas sobras de hábitats. Poucos sabem ou acreditam que certos representantes da fauna possuem maior importância econômica para o ecossistema que os próprios animais domésticos (CARVALHO, 1978, p.15). 
O desmatamento descontrolado leva à extinção de diversas espécies da fauna e da flora causando danos ambientais irreparáveis. A aproximação do homem com animais silvestres pode causar doenças desconhecidas para a espécie humana. Um exemplo disso é o momento que estamos vivendo, em meio a uma pandemia, causada pelo coronavírus da Síndrome Respiratória Aguda Grave 2, a Covid-19, doença causada pela Sars-Cov-2. É importante destacar que o coronavírus, segundo Andersen et al. (2020), tem como hospedeiro um animal silvestre, antes da transferência zoonótica a humanos, causando a SARS-CoV-2, que mostra semelhanças ao coronavírus encontrado nos pangolins (Manis javanica) e de morcegos. De várias maneiras o homem foi se aproximando, cada vez mais e de forma desordenada desses animais, para obter benefícios da terra e, com isso, causando prejuízos como consequência (ZAGO, 2008).

Toda essa mudança nos ecossistemas causados pela espécie humana tem um efeito enorme, a curto e longo prazo, afetando toda a biodiversidade do planeta e principalmente as questões climáticas. Sendo assim, com o isolamento social e a paralisação das atividades percebemos nossos efeitos sobre meio ambiente. Segundo os dados da Agência Internacional de Energia (IEA) (2020), durante o isolamento o mundo deixou de liberar um milhão de toneladas de $\mathrm{CO} 2$ por dia, em especial pela diminuição de consumo de petróleo e carvão. É como se estivéssemos recebendo um aviso para darmos mais atenção às mudanças climáticas e o aquecimento global. Para Dias (2014) é de conhecimento amplo que a mudança no clima tem influência sobre a vida de todos e possui efeitos irreparáveis sobre o planeta.

Esse fenômeno tem desestabilizado a sociedade e o meio ambiente de uma maneira global e sem precedentes. Os cientistas alertam sobre as mudanças climáticas há décadas, como nos resultados apresentados pelas Relatorias do Painel Internacional sobre Mudanças Climáticas (IPCC), exposto por Dias (2014). E agora, no momento em que nos encontramos em meio a uma pandemia e em isolamento, podemos observar o que acontece quando reduzimos a emissão de poluentes, diminuindo o fluxo de automóveis e das atividades industriais.

Sendo assim, não podemos agir da mesma forma após a pandemia passar, é preciso mudar para conseguirmos um equilíbrio a longo prazo. E, contrariando os que diziam que não podíamos parar, percebemos que várias atividades agora suspensas podem sim, parar. Se não conseguirmos conscientizar a sociedade de que é possível desacelerar, corremos o risco de quando voltarmos termos um boom na emissão de poluentes para tentar recuperar a economia a qualquer custo (SAN MARTIN, M.; SAN MARTIN, M., 2020).

Os ambientalistas e os pesquisadores da área ambiental alertam para os problemas atuais e como eles podem se agravar. Segundo Meneguzzi (2011) o aumento da temperatura tem forte relação com a elevação de gases de efeito estufa, especialmente de dióxido de carbono aumentando a partir do 
início da Era Industrial. A partir disso, é preciso considerar as mudanças climáticas e uma economia de baixo carbono. Quando conseguirmos superar essa pandemia vamos voltar para qual mundo? Continuaremos agindo da mesma forma e fazendo as mesmas coisas? Este trabalho visa questionar, sob a ótica de ambientalistas do Rio Grande do Sul, qual seria o melhor para o meio ambiente,

\section{Metodologia}

Este estudo surgiu pelos questionamentos e inquietações trazidas pelo pensador francês Bruno Latour, em seu texto traduzido por Déborah Danowski "imaginando gestos que barrem o retorno ao consumismo e à produção insustentável pré-pandemia".

No campo dos estudos qualitativos a pesquisa teve como procedimento a coleta de dados por meio de questionário semiestruturado. Iniciou-se a pesquisa ao enviar o e-mail convite com o questionário para cinco ambientalistas que representam projetos ambientais no estado do Rio Grande do Sul (RS). Somente quatro representantes dos projetos retornaram o e-mail: Praia Limpa Torres, Ecosurf/RS, Eco Imbé e Greenpeace/POA.

Inicialmente, as questões foram sugeridas a partir do texto de Bruno Latour, inseridas no questionário e acompanhadas do texto traduzido para leitura dos participantes da pesquisa. Ao final do questionário, foi encaminhado - Termo de Consentimento Livre e Esclarecido. Todos os participantes concordaram em ter seu nome publicado na pesquisa, assim como os nomes dos projetos ambientais.

Posteriormente, para o tratamento dos dados obtidos optou-se pela análise de conteúdo de Laurence Bardin (2011). A função principal na Análise de Conteúdo é levar a um olhar crítico do pesquisador. Para Bardin na realização da análise é necessário rigor, dedicação, foco nas mensagens e nas categorias-temáticas. Sendo assim, a análise de conteúdo compreende algumas etapas importantes como: exclusão mútua (cada elemento não pode existir em mais de uma categoria); homogeneidade (um único tema principal deve governar a sua organização); a categoria anterior depende da rigorosidade nesta etapa; pertinência (os documentos devem ter correlação com os objetivos da análise); objetividade e fidelidade (o material coletado deve ser codificado da mesma maneira, evitando diferenças entre eles) (BARDIN, 2011).

Para melhor compreensão das respostas analisadas, os educadores ambientais serão identificados pelas iniciais dos seus nomes, sendo: Praia Limpa Torres como AS; Ecosurf/RS como CAB; Eco Imbé como CS; e Greenpeace/POA como CDB. E para acesso as respostas completas das questões, as mesmas foram inseridas na integra em quadros ao longo do artigo, com destaque em negrito para os temas discutidos no texto. 


\section{Contextualizando os projetos}

\section{Praia Limpa Torres}

O projeto ambiental Praia Limpa Torres foi idealizado por Alexis Sanson, a sete anos. Hoje, Alexis é o atual coordenador do projeto, contando com grupos de voluntários para auxiliar nas decisões sobre as ações e eventos que o projeto realiza na cidade de Torres, litoral norte do Estado do Rio Grande do Sul. O projeto não recebe ajuda financeira do poder público, apenas de patrocinadores que simpatizam com as causas ambientais. O foco das atividades são: limpeza voluntária de praia e educação ambiental nas escolas do município, prioritariamente às séries iniciais. Junto com os voluntários o Projeto realiza as limpezas de praia que acontecem uma vez ao mês. E uma vez ao ano realizam o evento "Painel do Lixo". O evento conta com palestras e reuniões com outros projetos ambientais do litoral do RS. Também junto com outros projetos realiza a "Ação Lixo Zero" que acontece no final de cada verão. Tais atividades foram canceladas este ano por conta da pandemia.

\section{Ecosurf/RS}

O Instituto Ecosurf foi criado no ano de 2000, tendo sua matriz em Itanhaém, litoral Paulista. Segundo Cláudio A. Becker: "Aqui no RS intensificamos a atuação em 2018, quando assumi a frente da organização no Estado. Já fizemos várias ações de limpeza de praia, pesquisas, palestras e atividades em escolas. Não temos um "ponto" fixo, fazemos ações em todas as praias, chegando a fazer simultaneamente oito ações em praias diferentes em 2019" (CAB).

O Instituto se constitui como uma organização brasileira da sociedade civil, sem fins econômicos, dedicada ao empoderamento dos surfistas e dos povos do mar, para a atuação em causas públicas, proteção dos oceanos e educação socioambiental. CAB ressalta que "o Instituto Ecosurf abrange todo $o$ Brasil e possui pontos focais em alguns países como Portugal, EUA, França, Itália e Marrocos".

Sua atuação é principalmente no RS, mas também há envolvimento em projetos de abrangência nacional. Todas as ações do Ecosurf são padronizadas, em vários estados possuem voluntários que realizam atividades como as descritas por CAB: "educação ambiental, atividades de pesquisa e despoluição de ambientes costeiros, participação em grupos de tomada de decisão, combate às alterações climáticas, políticas públicas. Todos voltados principalmente as metas da ODS14". CAB explica que este ano antes da pandemia estavam com várias ações agendas (ações de educação ambiental em escolas e limpezas de praia). Conseguiram realizar algumas antes do isolamento total. Uma delas a limpeza de praia, com mais de 12 mil itens retirados do ambiente, catalogados e destinados para reciclagem. Aqueles que não podem ser reciclados são encaminhados para os locais corretos de descarte. Os dados contabilizados vão para um banco de dados e são 
enviados para compor o relatório da ONU. Segundo CAB o Ecosurf é o organizador oficial da campanha mares limpos da ONU Meio Ambiente no Brasil.

Com 0 isolamento e a dificuldade de realizar as ações, o Instituto Ecosurf reformulou suas atividades e iniciou ações sociais no RS e ações de educação ambiental on-line, além de algumas ações em momentos de crise social como agora, onde já fizemos várias doações de cestas básicas (em torno de $800 \mathrm{~kg}$ de alimentos) e materiais de higiene para uma Cooperativa de Catadoras Chefes de Família e estamos fazendo uma campanha do agasalho em várias praias e cidades simultaneamente.

\section{Eco Imbé}

O Projeto ambiental Eco Imbé foi idealizado por Cleverton da Silva, há dois anos. Apesar de ser relativamente novo entre os outros projetos que fazem parte desta pesquisa, o Eco Imbé já participa de ações simultâneas e realiza diversas atividades educativas em sua cidade. CS descreve suas atividades relacionadas com o meio ambiente como: "Limpezas de Praia, Palestras educativas ambientais, produção de placas de conscientização, parceria com outros grupos voluntários, empréstimo de material para conscientização ambiental. Coletores, Bituqueiras, luvas...etc".

Assim como os outros projetos o Eco Imbé precisou mudar algumas ações devido o atual momento que o país está passando. Atualmente realiza atividades online como entrevistas e a Ação do Dia Mundial da Limpeza que este ano está com uma proposta diferenciada usando a hashtag \#eucuidodomeuquadrado. CS realiza algumas atividades em sua cidade, mas sem incentivar a quebra do isolamento. As atividades são realizadas por ele sem a ajuda de voluntários.

\section{Greenpeace/POA}

Cinttia Bordini conta que há dez anos realiza as atividades sobre meio ambiente e sustentabilidade do Greenpeace, Porto Alegre/RS. As atividades são gratuitas e destinada a todos os níveis de ensino, instituições filantrópicas e empresas. " $E$, anualmente, organizamos junto a outras organizações $e$ iniciativas cidadãs, o Dia Mundial da Limpeza que acontece no terceiro sábado de setembro" (CDB).

O grupo de voluntários do Greenpeace de Porto Alegre foi o primeiro grupo de voluntários da organização, aqui no Brasil. Criado em 1994, o grupo vem promovendo desde então uma série de eventos, não só na capital, mas também em cidades próximas, como as cidades litorâneas, para semear, na população sul-rio-grandense, a esperança de um futuro melhor para o planeta. Sua missão é propagar o conhecimento sobre a importância de um meio ambiente equilibrado.

revista brasileira

educação ambiental 
O grupo de voluntários desenvolve atividades que permitam a todos conhecer o trabalho do Greenpeace e suas campanhas. Para disseminar ainda mais esse conhecimento, o grupo dá atenção também às crianças, pensando nos resultados a longo prazo, realizando muitas atividades em escolas, que visam apresentar também a história da organização.

\section{Resultados}

O texto Latour diz que a primeira lição do coronavírus foi que: "De fato, ficou provado que é possível, em questão de semanas, suspender, em todo o mundo e, ao mesmo tempo, um sistema econômico que até agora nos diziam ser impossível desacelerar ou redirecionar" (2020, p.1). Corroborando com Latour, Boaventura de Sousa Santos escreve que "A ideia conservadora de que não há alternativa ao modo de vida imposto pelo hipercapitalismo em que vivemos, cai por terra numa pandemia" (2020, p. 06). Para tanto, faz-se necessário aproveitar o momento e refletir sobre nossas interferências na natureza e, mais ainda, o que estamos dispostos a melhorar como indivíduos e no coletivo para que tenhamos uma harmonia entre natureza e sociedade.

Assim, é apresentado para discussão a questão 1: Quais as atividades agora suspensas que você gostaria que não fossem retomadas? A seguir no Quadro 1, as respostas dos participantes.

Quadro 1: Respostas Questão 1

\begin{tabular}{|l|c|}
\hline \multicolumn{1}{|c|}{ Respondente } & Resposta \\
\hline CDB & "Exploração de combustíveis fósseis. Shoppings Centers" \\
\hline AS & "Atividades que poluem os oceanos" \\
\hline CS & "Acredito que a atividade comercial de produção de embalagens \\
plásticas".
\end{tabular}

Fonte: elaboração das autoras.

A pandemia de Covid-19 vem demonstrando que existe a possibilidade em criar novas medidas sustentáveis de se viver no planeta. As respostas sobre a questão 1, trazem pautas importantes que vão ao encontro desta ideia, como o consumo desenfreado de produtos industrializados. Sendo a indústria uma grande consumidora de combustíveis fósseis, que utiliza cada vez mais embalagens plásticas (um produto do petróleo) gerando ainda mais lixo. Em última instância tudo isso acaba indo parar nos oceanos. 
Alterações físicas no meio ambiente são um reflexo do que embasa a modernidade, que, segundo Latour (2016) caracteriza-se pela separação radical entre a natureza e a cultura. Não é de hoje que o homem é responsável pelas mudanças radicais do meio ambiente e por desastres ambientais, especificamente no Brasil. Alguns deles como o ocorrido em 1980, quando o Polo Petroquímico de Cubatão (SP) despejava no ar toneladas de gases tóxicos, gerando uma névoa venenosa que afetava o sistema respiratório e gerava bebês com deformidades físicas. O Polo contaminou também água e solo da região, trazendo chuvas ácidas, explosões, incêndios e deslizamentos na Serra do Mar, que ficou conhecida como "Vale da Morte" (KLANOVICZ; FERREIRA FILHO, 2019).

Secas atingiram o estado do Amazonas em uma das regiões de maior disponibilidade hídrica do país e do planeta. Em 2009 e 2012, este mesmo estado sofreu inundações que superaram os níveis históricos. Em março de 2004, o ciclone Catarina atingiu o litoral norte do RS e o litoral sul de Santa Catarina (SC), causando danos na área urbana e rural concentradas numa faixa de aproximadamente $100 \mathrm{~km}$ (DIAS, 2014). Fortes inundações afetaram SC em 2008, igualmente Alagoas e Pernambuco em 2010. A região Serrana do Rio de Janeiro foi acometida por graves desastres em 2011. Envolvendo inundações e deslizamentos de terra chegando a quase mil mortos. Em 2010, iniciava-se uma forte seca atingindo três em cada quatro municípios do Nordeste, que decretaram situação de emergência em 2013, sendo considerada a mais longa dos últimos 50 anos (FREITAS et al., 2014).

Em novembro de 2015, Mariana em Minas Gerais, sofreu com o rompimento da barragem pertencente à Mineradora Samarco S.A., provocando a liberação de uma onda de lama de mais de dez metros de altura, contendo 60 milhões de metros cúbicos de rejeitos. Em Minas Gerais ocorreram desastres ambientais com mineração em 2001 em Nova Lima, Miraí em 2007 e em Itabirito no ano de 2014 (LACAZ; PORTO; PINHEIRO, 2017). Como também, em 2019 com o derramamento de petróleo ou óleo bruto na faixa de $4.334 \mathrm{~km}$, atingindo 11 estados do nordeste e sudeste brasileiro, atingindo 120 municípios e 724 localidades (PENA, et al. 2020).

Nesse contexto, Latour (2016) diz que a condição de que humanos e não-humanos existam é uma relação de interdependência, o que como narrado anteriormente não vem acontecendo. Para o filósofo é preciso que haja um respeito ético entre homem e natureza. Com isso, é possível perceber nas respostas dos entrevistados, que se dedicam aos cuidados com o meio ambiente, a preocupação de que a responsabilidade com a natureza deveria ser de todos os seres humanos.

$\mathrm{Na}$ questão 2, os entrevistados são levados a pensar sobre a resposta dada a questão 1, sendo indagados da seguinte forma: Descreva por que essa atividade lhe parece prejudicial/supérflua/perigosa/sem sentido e de que forma o seu desaparecimento/suspensão/ substituição tornaria outras atividades que 
você prefere mais fáceis /pertinentes. Abaixo, no Quadro 2, encontram-se as respostas dos participantes:

Quadro 2: Respostas Questão 2.

\begin{tabular}{|c|c|}
\hline Respondente & Resposta \\
\hline CDB & $\begin{array}{c}\text { "A exploração de fósseis é um grande desastre Ambiental em todos os } \\
\text { cantos do planeta. Poluir mares e toda a vida marinha, polui o ar e é } \\
\text { responsável pelo aquecimento do planeta. Sem dar lugar às geniais } \\
\text { Energias Renováveis, menos poluidoras e que geram mais empregos } \\
\text { saudáveis. O consumismo dos shoppings deve parar. Aprendemos a } \\
\text { consumir o que não precisamos! Voltar a frequentar os pequenos } \\
\text { comércios dos bairros é mais saudável e mais humano. Sem tantos } \\
\text { apelos comerciais a aquisição de supérfluos, que explicam o colapso da } \\
\text { produção industrial que é altamente poluidora." }\end{array}$ \\
\hline AS & $\begin{array}{l}\text { "Os oceanos são o berçário da vida no planeta, portanto toda atividade } \\
\text { que o agrida, agride a humanidade e todas espécies vivas do planeta" }\end{array}$ \\
\hline CS & $\begin{array}{c}\text { "Já se tem meios de substituir este material plástico por outros } \\
\text { biodegradáveis" }\end{array}$ \\
\hline CAB & $\begin{array}{c}\text { "No sistema econômico capitalista e linear (extrair, produzir, usar e } \\
\text { descartar), somos medidos pelo que consumimos. Nos grupos que as } \\
\text { pessoas querem participar, como querem ser vistas, tudo é balizado pelo } \\
\text { poder de consumo. Existe uma corrida pelo "vencer", e este "vencer" é o } \\
\text { seu potencial de consumo. E o sistema de produção linear, nos leva a } \\
\text { cada ano que passa gastarmos mais rápido os recursos naturais, do que a } \\
\text { capacidade da terra em repô-los devido ao grande consumismo, a conta } \\
\text { deste "cheque especial" está impagável. Sem contar que muitos pouco } \\
\text { consomem, enquanto a maioria da população mundial não tem nem } \\
\text { como consumir. Não podemos pensar em sustentabilidade ou } \\
\text { desenvolvimento sustentável com o modelo atual. Lembrando que para } \\
\text { falar em desenvolvimento sustentável, devemos pensar em três pilares, o } \\
\text { ambiental, o social e o econômico". }\end{array}$ \\
\hline
\end{tabular}

Fonte: elaboração das autoras.

Para CDB a "A exploração [combustíveis] de fósseis é um grande desastre Ambiental em todos os cantos do planeta. [...] Sem dar lugar às geniais Energias Renováveis, menos poluidoras e que geram mais empregos saudáveis". Assim, como em muitos lugares ao redor do mundo, o Brasil é dependente de materiais a base de petróleo e seus derivados. No entanto, as fontes renováveis lentamente conquistam seu espaço e passam a mostrar ganhos significativos em produtividade e eficiência econômica. A energia eólica é uma forma de obter energia, sem esgotar os recursos naturais, assim como a energia solar, energia hídrica, energia das ondas e marés e energia de biomassa. As usinas de geração de energia são, frequentemente, menores que as usinas tradicionais e, geralmente, encontram-se em áreas rurais de baixa densidade demográfica. Devido a essa característica a construção dessas 
usinas necessita uma maior quantidade de mão de obra, com isso gerando mais empregos em diversas localidades (SIMAS; PACCA, 2013).

Mesmo com essas considerações para o uso das energias renováveis, ao longo das últimas décadas, o que podemos perceber em relação à espécie humana e sobre sua condição de ser no planeta é o descaso com outras formas de vida e pouca confiança nas falas dos ambientalistas. Sobre isso a resposta de AS nos faz pensar sobre: "Os oceanos são o berçário da vida no planeta, portanto toda atividade que o agrida, agride a humanidade e todas espécies vivas do planeta" e com isso CS completa: "Já se tem meios de substituir este material plástico por outros biodegradáveis". E se já temos as soluções, por que não conseguimos mudar os hábitos? Novamente Latour (2020) elucida,

\begin{abstract}
Uma coisa leva a outra: se cada um de nós começar a fazer esse tipo de pergunta sobre cada aspecto de nosso sistema de produção, podemos nos tornar efetivos interruptores da globalização - tão efetivos, pois somos milhões, quanto o famoso coronavírus em sua maneira única de globalizar o planeta. $O$ que o vírus consegue com a humilde circulação boca a boca de perdigotos - a suspensão da economia mundial - nós começamos a poder imaginar ser para nós também possível, que nossos pequenos e insignificantes gestos, acoplados uns aos outros, conseguirão: suspender o sistema produtivo (p. 2).
\end{abstract}

CB faz uma importante colocação quando lembra: "Sem contar que poucos consomem muito, enquanto a maioria da população mundial não tem nem como consumir. Não podemos pensar em sustentabilidade ou desenvolvimento sustentável com o modelo atual". Para Ailton Krenak "[...] há uma sub-humanidade que vive numa grande miséria, sem chance de sair dela e isso também foi naturalizado" (2020, s/p). O problema do coronavírus e da má relação do homem com a natureza não são só problemas de saúde e meio ambiente, são também um problema social. Esse problema social atinge com força as pessoas de baixa renda como CB mencionou, pessoas que não tem o que consumir, impedindo que esses sujeitos façam o isolamento no caso da pandemia. CAB também chama a atenção para o desenvolvimento sustentável e os seus pilares: ambiental, econômico e social, que devem ser considerados quando pensamos em normas (SCHMITZ, 2019a) e práticas e comportamentos para o desenvolvimento sustentável (SCHMITZ, 2019b).

Na sequência, a questão 3 pediu aos entrevistados que respondessem a seguinte pergunta: Que medidas você sugere para facilitar a transição para outras atividades daqueles trabalhadores/empregados/agentes/empresários que não poderão mais continuar nas atividades que você está suprimindo? 0 Quadro 3 apresenta as respostas. 
Quadro 3: Respostas Questão 3.

\begin{tabular}{|c|c|}
\hline Respondente & Resposta \\
\hline CDB & $\begin{array}{c}\text { "Retomada governamental do Investimento em Energia Solar e sua } \\
\text { proliferação. Novos/antigos empregos criados como jardineiros para } \\
\text { escolas e praças, sapateiros, costureiras, artesãos, etc. Consultores } \\
\text { para hortas urbanas economia circular. }\end{array}$ \\
\hline AS & $\begin{array}{c}\text { "Capacitação para novos empregos que surgirão no futuro próximo, } \\
\text { como por exemplo, o APP UBER que anos atrás era um trabalho } \\
\text { inimaginável" }\end{array}$ \\
\hline CS & $\begin{array}{c}\text { "Sugiro que estes se atualizem, afinal, evoluir a produção de produto, } \\
\text { também é pensar no futuro da própria empresa onde trabalham" }\end{array}$ \\
\hline "Acredito em uma mudança, que não é a curto prazo, mas devemos \\
começar agora. Economia circular. Existem exemplos, como o da \\
Holanda, onde estão se preparando para em 2050 serem totalmente \\
circulares"
\end{tabular}

Fonte: elaboração das autoras.

Pensar em soluções para os problemas atuais se faz necessário. Aliás, essa é uma das proposições deste artigo e de Latour (2020), quando diz:

Daí a importância fundamental de usar este tempo de confinamento imposto pela pandemia para descrevermos, primeiro cada um por si, depois em grupo, aquilo a que somos apegados, àquilo de que estamos dispostos a nos libertar, as cadeias que estamos prontos a reconstituir e aquelas que, por meio do nosso comportamento, estamos decididos a interromper (p. 01).

Assim, AS diz que é preciso "[...] Capacitação para novos empregos que surgirão no futuro" e CS na mesma linha fala "Sugiro que estes se atualizem, afinal, evoluir a produção de produto, também é pensar no futuro da própria empresa onde trabalham". Em uma abordagem diferenciada CDB sugere a retomada de serviços que estão em desaparecimento como: [...] "sua proliferação. Novos/antigos empregos criados como jardineiros para escolas e praças, sapateiros, costureiras, artesãos, etc., consultores para hortas urbanas economia circular". É interessante pensar na retomada de atividades considerados como "ofícios" no sentido do fazer mais artesanal, na tentativa de reconexão com o que estamos perdendo. Por fim, CAB traz um novo conceito em sua resposta e escreve: "Acredito em uma mudança, que não é a curto prazo, mas devemos começar agora: Economia circular". A Economia Circular é vista como uma ruptura ao modelo capitalista vigente de abusos e usos 
indevidos dos recursos naturais e propõe a circulação de bens extraídos em uma cadeia produtiva integrada. Assim:

A criação de sistemas de reparo, reuso e remanufatura, além de uma reciclagem efetiva, permite que matérias-primas introduzidas em cadeias de produção mantenham ou mesmo aumentem seu valor. Portanto, a economia circular é um sistema industrial intencionalmente reparador ou regenerativo, que traz benefícios operacionais e estratégicos, bem como um enorme potencial de inovação, geração de empregos e crescimento econômico. Ademais, possui o objetivo de manter produtos, componentes e materiais em circulação para tirar o máximo de valor e utilidade, através da distinção entre ciclos técnicos e biológicos (SEHNEM; PEREIRA, p. 36, 2019)

Esse conceito foi trazido por $C D B$ e por $C A B$ evidencia, para os indivíduos envolvidos em atividades ambientais, a economia circular como uma opção viável para o reequilíbrio ambiental.

A questão 4 propôs pensar: Quais as atividades agora suspensas que você gostaria que fossem ampliadas/retomadas ou mesmo criadas, a partir do zero?

Quadro 4: Respostas Questão 4.

\begin{tabular}{|c|c|}
\hline Respondente & Resposta \\
\hline CDB & $\begin{array}{c}\text { Floriculturas, Alfaiataria, Estofadores... Escolas sob uma ótica } \\
\text { integradora, mais humana, criativa, sem sobrecarga de horas em } \\
\text { atividades que não contribuem para o fomento da ciência, } \\
\text { criatividade e Educação Artística/Musical/Teatral }\end{array}$ \\
\hline AS & $\begin{array}{l}\text { "Atividades relacionadas à educação ambiental poderiam ser } \\
\text { ampliadas nas comunidades em razão da constatação da retração das } \\
\text { atividades poluentes e do planeta mais limpo e preservado". }\end{array}$ \\
\hline CS & $\begin{array}{c}\text { "Acredito que os movimentos voluntários já estão ganhando cada } \\
\text { vez mais força, ao natural. O retorno será com mais força ainda, devido } \\
\text { ao grande número e disseminação de informações relacionadas ao meio } \\
\text { ambiente" }\end{array}$ \\
\hline $\mathrm{CAB}$ & $\begin{array}{c}\text { "Eu gostaria que todas recomeçassem a partir do zero! Utopia! Mas a } \\
\text { educação precisa retomar com um enfoque diferente, que ensine a } \\
\text { pensar e que tenha enfoque no desenvolvimento sustentável. A } \\
\text { circulação de pessoas, com mais empatia, como a que estamos vendo } \\
\text { em muitos agora" }\end{array}$ \\
\hline
\end{tabular}

Fonte: elaboração das autoras. 
Esta questão propôs pensar em qual futuro queremos estar, após a pandemia. Se chegamos até esse momento e, de forma desordenada com tantos problemas, é preciso estar atento para as mudanças, é preciso sonhar em um mundo mais solidário e sustentável. Assim, os entrevistados, ambientalistas importantes peças que fazem parte dessa mudança, com projetos que visam de alguma forma, impactar positivamente a sociedade e 0 meio ambiente e nos ajudam a refletir sobre o que pode-nos levar a essa mudança efetiva. CAB e CDB trazem para a discussão a escola e a educação, pilares fundamentais de qualquer sociedade. CAB diz: "gostaria que todas recomeçassem a partir do zero! Utopia! Mas a educação precisa retomar com um enfoque diferente, que ensine a pensar e que tenha enfoque no desenvolvimento sustentável". CDB completa: "Escolas sob uma ótica integradora, mais humana, criativa, sem sobrecarga de horas em atividades que não contribuem para o fomento da ciência, criatividade e Educação Artística/Musical/Teatral".

Lima et al. (2019) em seu trabalho trazem a preocupação de Bruno Latour com o apagamento das redes que sustentam a Ciência já na escola. E, aqui encontra-se o perigo, pois temos como fonte de "verdade" apenas um dos polos (sociedade/sujeito ou natureza/objeto) e não todas as proposições que se deslocam formando a rede e os atores, fazendo com que o aluno não tenha um conhecimento profundo sobre temas ambientais e científicos e, por vezes, quando adultos caiam em armadilhas como as fake news. Para tanto:

[...] ao invés de ensinar simplesmente que a Terra é redonda ou que vacinas funcionam, pode-se discutir quais são as evidências que sustentam tais ideias (desnaturalizando a noção de que se está diante de um fato autônomo e óbvio, mas de uma proposição que é articulada com uma rede de dados, experimentos, teorias, equipamentos e cientistas) e como essa rede tenta ser desarticulada por programas concorrentes e vice-versa. Nesse contexto, pode-se discutir, também, as questões de poder e de disputa que envolvem a prática científica (LIMA et al., 2019, p. 171).

Por isso, são tão importantes as reflexões trazidas por CAB e CDB, quando pensam na Educação Ambiental: "Atividades relacionadas à educação ambiental poderiam ser ampliadas" e "Acredito que os movimentos voluntários já estão ganhando cada vez mais força, ao natural. O retorno será com mais força ainda, devido ao grande número e disseminação de informações relacionadas ao meio ambiente". Como demonstrado por Schmitz e Rocha (2018), as práticas de educação ambiental contribuem para o desenvolvimento de atitudes sustentáveis.

A última questão, apresentado no Quadro 5, pergunta: Como construir 
de saúde mundial nos proporciona? Torna-se uma questão chave e fecha o rol de reflexões propostas por Latour em seu texto, aliada aqui às contribuições dos ambientalistas que trabalham em prol do meio ambiente no litoral do RS. Segundo AS para construir sociedades sustentáveis é possível: "Buscando através da pesquisa acadêmica soluções sustentáveis para nossa sociedade". Muito tem se falado da importância das universidades e das pesquisas científicas nesse período em que o coronavírus nos paralisa, mas o papel das universidades e das pesquisas são, desde sempre, fundamentais para as ciências. São nesses espaços que se formam as redes e os atores que proporcionam as proposições científicas, nos termos latourianos e que promovem o desenvolvimento da ciência.

Já para CDB e CS é preciso pensar na redução do "[...] consumo de supérfluos $(C D B)$ e [...] principalmente reduzindo o uso e consumo de objetos de plástico e um retorno global sustentável seguindo corretamente os famosos ' $R$ 's'" (CAB). Talvez aqui seja fundamental pensar mais uma vez no papel da educação e, principalmente da educação ambiental, que tem sido um componente importante para se repensar as teorias e práticas que fundamentam as ações educativas, sendo em contextos formais e/ou informais, orientando para a solução dos problemas voltados para a realidade local. É importante que ocorra um processo participativo e permanente, de maneira que não seja apenas e exclusivamente informativa. É imprescindível a prática, de modo a desenvolver e incutir uma consciência crítica sobre os problemas ambientais (MEDEIROS et al., 2011).

Quadro 5: Respostas Questão 5.

\begin{tabular}{|c|c|}
\hline Respondente & Resposta \\
\hline CDB & $\begin{array}{c}\text { "Trocando ideias com amigos, vizinhos, pressionando os governantes a } \\
\text { investir na s instituições públicas e reduzindo o consumo de supérfluos e } \\
\text { principalmente reduzindo o uso e consumo de objetos de plástico". }\end{array}$ \\
\hline AS & $\begin{array}{c}\text { "Buscando através da pesquisa acadêmica soluções sustentáveis para } \\
\text { nossa sociedade. Precisamos mudar nossos hábitos de consumo." }\end{array}$ \\
\hline CS & $\begin{array}{c}\text { "Na minha concepção, acredito piamente que resíduos, lixo, enfim, } \\
\text { um retorno é sinônimo de recurso. Podemos sim começar a vislumbrar } \\
\text { "R's". Repensar para Recusar, Reduzir, Reciclar e Reutilizar" }\end{array}$ \\
\hline CAB & "Como citei anteriormente, o futuro é a economia circular" \\
\hline
\end{tabular}

Fonte: elaboração das autoras. 


\section{Considerações Finais}

As respostas que os ambientalistas formularam nas questões sobre temas emergentes e urgentes nos dias atuais fazem conexões com um passado manchado por desastres ambientais e um presente e futuro possíveis após pandemia.

Traçando um paralelo com a perspectiva Latouriana, abordada na obra "Políticas da Natureza: como fazer ciência na democracia", o autor deixa evidente que "[...] as ciências entram na democracia, de sorte a redefinir a vida pública como composição progressiva de um mundo comum" (LATOUR, 2004, p. 39). É urgente e necessário pensar o quanto o movimento do negacionismo científico interfere nas políticas públicas relativas ao meio ambiente. Nesse movimento de repensar nossas ações como sujeitos-cidadãos, os projetos ambientais têm um papel fundamental, por meio da educação ambiental, e na elaboração de políticas públicas para o meio ambiente. São esses movimentos que garantem aos sujeitos perceberem as redes e as preposições que se deslocam a fim de combater o negacionismo e, consequentemente, tomar decisões mais conscientes no dia a dia.

A educação ambiental apresenta, em toda a sua dinâmica, a importância da participação individual e coletiva no cuidado com ciclo natural da vida. A conscientização das questões ambientais vem a partir do encontro com 0 equilíbrio, nas relações constituídas entre os seres vivos e os recursos naturais. Com isso, o despertar das ações, dos valores ambientais e sociais na escola e na comunidade se inicia para que, aos poucos, as ações se multipliquem e permeiem outros locais e outras pessoas. Chagando à participação efetiva e construtiva, com o respeito à biodiversidade e a consequente melhoria na qualidade de vida dos indivíduos.

\section{Agradecimentos}

A Coordenação de Aperfeiçoamento de Pessoal de Nível Superior (CAPES) e aos entrevistados pela presteza em atender ao nosso convite, Alexis Sason do Praia Limpa Torres, Cláudio Becker do Ecosurf/RS, Cleverton da Silva do Eco Imbé e Cinttia Bordini do Greenpeace Porto Alegre.

\section{Referências}

ANDERSEN, K. G.; RAMBAUT, A., LIPKIN, W. I.; HOLMES, E. C.; GARRY, R. F. A origem proximal do SARS-CoV-2. Nature Medicine, v. 26, p. 450-452, 2020.

BARDIN, L. Análise de conteúdo. São Paulo: Edições 70, 2011.

BAUMAN, Z. Amor líquido. Rio de Janeiro: Jorge Zahar, 2004 
CARVALHO, J. C. M. Atlas da Fauna Brasileira. São Paulo: Companhia e Melhoramentos, 1978.

DIAS, G. F. Mudanças Climáticas e Você: cenários, desafios, governança, oportunidades, cinismo e maluquices. 1 ed. São Paulo: Gaia, 2014.

FREITAS, C. M. et al. Desastres naturais e saúde: uma análise da situação do Brasil. Ciênc. Saúde coletiva, Rio de Janeiro, v. 19, n. 9, p. 3645-3656, 2014.

GUIMARÃES, M. A dimensão ambiental na educação. Campinas: Papirus, 1995.

IEA. Agência Internacional de Energia. IEA Website, 2020. Disponível em: https://www.iea.org/reports/monthly-oil-price-statistics. Acesso em: 12 jun. 2020.

KRENAK, A. O amanhã não está à venda. São Paulo: Companhia das Letras, 2020. E-Book.

KLANOVICZ, J.; FERREIRA FILHO, C. B. A fabricação de uma cidade tóxica: A Tribuna de Santos e os desastres tecnológicos de Cubatão (Brasil) na década de 1980. Cadernos do CEOM, Chapecó, v. 31, n. 48, p. 10-20, jun./2018.

LACAZ, F. A. C.; PORTO, M. F.S.; PINHEIRO, T. M. M. Tragédias brasileiras contemporâneas: o caso do rompimento da barragem de rejeitos de Fundão/Samarco. Revista Brasileira de Saúde Ocupacional, São Paulo, v. 42, 2017.

LATOUR, B. Políticas da natureza: como fazer ciência na democracia. Tradução de Carlos Aurélio Mota de Souza. São Paulo: Editora EDUSC, 2004.

LATOUR, B. Jamais fomos modernos: ensaio de antropologia simétrica. 3 ed. Rio de Janeiro: Editora 34, 2016.

LATOUR, B. Imaginando gestos que barrem o retorno ao consumismo e à produção insustentável pré-pandemia. Tradução: Débora Danowski. 2020 Clima Info, 3 abr. 2020. Disponível em: $<$ https://climainfo.org.br/2020/04/02/barrar-producao-insustentavel-eonsumismo/>. Acesso em: 09 jun. 2020.

LIMA, N. W.; VAZATA, P. A. V.; MORAES, A. G.; OSTERMANN, F.; CAVALCANTI, C. J. de H. Educação em Ciências nos Tempos de PósVerdade: Reflexões Metafísicas a partir dos Estudos das Ciências de Bruno Latour. Revista Brasileira De Pesquisa Em Educação Em Ciências, v. 19, p. 155-189, 2019.

MEDEIROS, M. C. S.; RIBEIRO, M. C. M.; FERREIRA, C. M. A. Meio ambiente e educação ambiental nas escolas públicas. Âmbito Jurídico, Rio Grande, n. 92, set./2011.

MENEGUZZI, N. L. G. Mudanças climáticas, saúde e trabalho: o direito ante o ambiente em transformação. 2011. Dissertação (Mestrado em Direito Ambiental) - Universidade de Caxias do Sul. Caxias do Sul: UCS, 2011. 
Milícia na Muzema é chefiada por major da PM, suspeito de controlar construções de imóveis irregular. G1Rio, 2019, Disponível em: $<$ https://g1.globo.com/ri/rio-de-janeiro/noticia/2019/04/12/milicianos-dominamconstrucao-e-venda-de-imoveis-irregulares-na-muzema-onde-prediosdesabaram.ghtml>. Acesso em: 07 jun. 2020.

PENA, P. G. L.; NORTHCROSS, A. L.; LIMA, M. A. G.; RÊGO, R. C. F. Derramamento de óleo bruto na costa brasileira em 2019: emergência em saúde pública em questão. Caderno de Saúde Pública, v. 36, n. 2, 2020. DOI: 10.1590/0102-311X00231019.

SANTOS, B. S. A cruel pedagogia do vírus. São Paulo: Boitempo, 2020. Ebook.

SAN MARTIN, M. C.; SAN MARTIN M. C. Condições atuais das emissões dos poluentes atmosféricos durante a quarentena da Covid-19 e as perspectivas futuras. Boletim de Conjuntura (BOCA), Boa Vista, ano II, v. 2, n. 5, p. 85-96, 2020.

SCHMITZ, G. L.; ROCHA, J. B. T. Environmental education as a tool to improve children's environmental attitudes and knowledge. Education (Rosemead), v.15, n. 2, p. 15-20, 2018.

SCHMITZ, G. L. Norms and Values for Sustainable Development. In: LEAL FILHO, W. (org.) Encyclopedia of Sustainability in Higher Education. Springer, Cham. 2019a.

SCHMITZ G.L. Behavioral Aspects and Change Management for Sustainable Development. In: Leal Filho W. (eds) Encyclopedia of Sustainability in Higher Education. Springer, Cham. 2019b.

SEHNEM, S.; PEREIRA, S. C. F. Rumo à Economia Circular: Sinergia Existente entre as Definições Conceituais Correlatas e Apropriação para a Literatura Brasileira. RECADM, v.18, n.1, p.35-62, jan-mar./2019.

SIMAS, M., PACCA S. Energia eólica, geração de empregos e desenvolvimento sustentável. Estudos avançados, São Paulo, v. 27 n. 77, p. 99-116, 2013.

ZAGO, D. C. Animais da fauna silvestre mantidos como animais de estimação. 2008. Especialização (Monografia de Especialização) - Programa de PósGraduação em especialização Ambiental - Universidade Federal de Santa Maria. Santa Maria: UFSM, 2008. 